ment de la Seine et la Ville de Paris, as November 16 in the obituary notice in the Government Gazette, but as November 15 in the register of Le Père Lachaise cemetery, where he was buried, and also on the gravestone which, according to Persoon's testamentary instructions (and for which he composed the inscription), was "simple and vertical".

I am indebted for help in preparing this article to
Dr. M. A. Donk of the Rijksherbarium, Leyden, for the loan of literature, and to Mr. P. Blum for translations from the Dutch.

2 Linnaeus, C. Philosophia botanica, 241 (1751) (translation by Ramsbottom, J., Proc. Linn. Soc. Lond., 151, 293; 1941).

'Franken, J. L. M., "Uit die Lewe van'n Beroemde Afrikaner, Christiaan Hendrik Persoon", Ann. Wniv. Stellenbosch, 15B, 4, $102 \mathrm{pp}$ (1937);, "A Note on a Visit to Christiaan Hendrik Persoon, Grave", J. South Afr. Bot., 4, 127 (1938), gives details of Persoon's sulted in the preparation of this article.

\title{
BIOLOGICAL ACTION OF FLUORIDES
}

$\mathrm{O}^{\mathrm{N}}$ October 25, the Bone and Tooth Society held a symposium on "Fluorides", under the chairmanship of Dr. H. A. Sissons. The large attendance and brisk discussion were indications of the present wide interest in this subject.

The symposium opened with a paper by Dr. G. N. Jenkins (King's College, Newcastle upon Tyne) on "The Mode of Action of Fluoride with Special Reference to Dental Effects". He summarized the three known effects of fluoride at physiological concentrations: (a) ionic exchange with hydroxyl of the apatite in the calcified tissues; $(b)$ influencing the precipitation of mineral from saturated solutions of calcium phosphate, resembling saliva; (c) inhibition and, in some cases with low concentrations, activation of enzymes. Since fluorapatite dissolves in acids less readily than hydroxyapatite it had long been thought teeth formed in areas with 'high' levels of fluoride (more than 1 p.p.m.) in the tap-water would be less soluble than those from 'low' fluoride areas-and direct comparisons of the tooth solubilities have confirmed this, although the differences are small. The action of fluoride in favouring mineral deposition suggested that it might reduce the rate of tooth decay by slowing up or even intermittently stopping the development of existing cavities.

With regard to enzyme inhibition, low concentrations of fluoride (5-10 p.p.m.) could reduce, and in some conditions such as a $p \mathrm{H}$ of $5 \cdot 0$, completely stop acid production from carbohydrate by salivary bacteria-a result which would be expected to slow down caries.

The crucial question of this anti-enzymatic theory of the action of fluoride in reducing caries was the guoride concentration in the muco-bacterial 'plaque' on the teeth. Whether it reached inhibitory levels and whether it varied with the fluoride of the drinkingwater were still unknown, but the work of Hardwick and Fremlin and their colleagues was likely to provide an answer shortly.

Information on those enzymes most sensitive to fluoride might provide a clue as to which were involved in the toxic reactions of the tissues. Unfortunately, the available information on fluoride sensitivity could not be compared since some enzymes had been studied in intact cells, others in mitochondria and others with crystalline preparations.

Dr. S. M. Weidmann (University of Leeds) described his work with Dr. J. A. Weatherell on the fluorotic lesions of bone. Although the bone effects showed considerable variation and obeyed no particular pattern, two marked features were bone formation and resorption. In most cases the newly formed bone appeared as localized, irregular outgrowths (exostoses), or caused a generalized thickening of bone.
Bone resorption usually developed from the endosteal area of shaft bone and progressed towards the periosteum, forming large cavities and frequently causing a widening of Haversian canals. It had been sug. gested that resorption was the primary action and the thickening represented a compensation to maintain the strength of the bone. As resorption was not the first reaction observed, Dr. Weidmann did not accept this view, but thought that resorption was a means of supplying the minerals needed for the calcification of the exostoses. The presence of wide seams of uncalcified matrix suggested that fluoride interfered with calcification. The matrix formed in fluorotoxicosis was more resistant to the attack of collagenase than that of non-fluorotic bone, but further work showed that this resistance was due to the exostoses being young bones with a high mucopolysaccharide content rather than the result of a pathological change caused by fluoride. Serum alkaline phosphatase rose, as in other bone dystrophies. Fluorotic bone was low in carbonate, and high in fluoride and magnesium, the calcium/phosphorus ratio being normal. Fluoride accumulation was not uniform throughout bone. Apart from blood flow, vascularity of bone and crystal size of bone mineral, its uptake seemed to be governed by a tendency to accumulate in those areas of bone which are known to be prone to exostosis formation.

Dr. A. M. Bond (Bedford College, University of London), in her paper on "Some Effects of Fluoride on General Metabolism", mentioned that the inhibition of enolase arrested glycolysis, thus leading to a diminished production of adenosine triphosphate and consequent failure of the energy supply to the cells. Also, the respiratory chain is affected by inhibition of succinic dehydrogenase. Soft tissues did not accumulate fluoride, the concentrations being normally less than 1 p.p.m. An acute lethal dose of a soluble fluoride produced severe gastro-intestinal distress with hæmorrhages in the gut and general hyperæmia. Excitation followed by paralysis of the nervous system and musculature occurred with respiratory distress and cyanosis. Instilling $5 \mathrm{~m} M$ sodium fluoride solution (that is, 95 p.p.m. fluorine) into a cat's stomach reduces to 50 per cent the secretion of hydrochloric acid in response to injected histamine and increases greatly the permeability of the mucosa to cations. In chronic fluorosis in rats, the numbers of oxyntic cells of the stomach were reduced. Appetite was depressed (even if the fluoride was injected, thus eliminating the effect of taste), gain in weight was reduced and thero was wasting of body tissues revealed both histologically and by a high urea output. Polyuria, low renal clearance values and histological evidence of necrotic nephrons proved the presence of impaired kidney function. Life was not 
shortened. It was stated that man is more sensitive to fluoride than experimental animals but that some adaptation could occur, for example, industrial workers exposed to fluoride showed more severe symptoms after a period of absence.

Dr. W. T. C. Berry discussed "Medical Effects especially in Relation to Fluoridation Levels". The average daily fluoride intake in Britain had been estimated as $0.6 \mathrm{mgm}$. for children, $1.3 \mathrm{mgm}$. for women and $1.8 \mathrm{mgm}$. for men. If the water contained 1 p.p.m. of fluoride, these intakes were approximately doubled for children and rose 70-80 per cent for adults. The diet of primitive man probably contained more fluoride than do modern diets, as presumably bones were chewed and, where salt was used, it was sea salt. The first sign of excessive intake in man was mottled enamel, sug gesting that the ameloblast was the most sensitive cell. It had been found in several countries that another type of enamel marking ('idiopathic mottling') decreased in incidence as the fluoride of the tap-water rose from zero to about 1 p.p.m., although evidence of a causal relationship (for example, a fall in incidence after a town water supply was fluoridated) was inadequate. There were preliminary reports that osteoporosis was unusually common in areas where water-borne fluoride was zero and that calcium balances in osteoporosis and Paget's disease improved with large intakes of fluoride.

No evidence had been produced in recent work to suggest that any harmful effects followed the fluoridation of water at the level of 1 p.p.m. At higher intakes, as with certain workers in the aluminium industry, gastritis and increased density of bone had been reported. Bone lesions had been found in the absence of reported evidence of renal damage, indicating that increased bone density occurred before renal change.

The symposium revealed the contrast between knowledge of the effects of fluoride and ignorance of the mechanisms, and the need for multi-disciplinary work. It was pointed out that even the well-known inhibition of enolase provided an uncertain explanation for the reduction of glycolysis by salivary bacteria. The observed effect was reduced acid production, whereas if enolase were inhibited the expected result would be the accumulation of one acid (phosphoglyceric) in place of the normal acid end-product (lactic), presumably with little effect on $p \mathrm{H}$.

G. N. Jenkins

\section{SPECIATION IN THE SEA}

$\mathrm{A}^{\mathrm{T}}$ $T$ a symposium arranged by the Systematics Association and the Challenger Society, and held at the Plymouth Laboratory of the Marine Biological Association of the United Kingdom, during September 27-29, the practical difficulties in examining the processes by which new species develop in marine habitats were comprehensively examined.

Throughout the meeting two factors were continually emphasized as restricting the progress towards a true appreciation of the problems of speciation. These were the need for more extensive taxonomic study of the plants and animals and the severe limitations on experimental work which the sea as an environment imposes. The contrasting features of the open ocean, the inter-tidal zone and benthic regions exposed fundamental differences of approach to the problem, with resultant divergence of opinion as to primary and secondary causes.

In the zooplankton, an example from the North Pacific Ocean illustrated the necessity for very large collections now available and for the genetical examination of living populations, unfortunately not yet possible. J. A. McGowan reviewed his work in that ocean on the pteropod Limacina helicina which occurs there in two forms: $A$, high spired, with striations, inhabiting the Sub-Arctic water mass; and $B$, short spired, with no striations, living in the Transition Zone, the Alaskan Gyral and the California Current. A form intermediate between $A$ and $B$ may occur in overlapping areas. The water circulation in the North Pacific is such that form $B$ must have been derived from $A$. Only those specimens, the genetic make-up of which allows them to inhabit Transition Zone water, survive there, and these, form $B$, become progressively more adapted to this water, and unsuitable genotypes of the parent populations tend to be eliminated. Eventually reproductive isolation may occur here.

A genetical study of the actual populations involved is of course a necessity to a full understanding of this problem. Whether or not the differences which separate these populations are genotypic or phenotypic is fundamental. This aspect of the subject was stressed by a number of speakers.

P. M. David gave a detailed account of the distribution of species of Sagitta. Bathypelagic species are more widely distributed than epi- and meso-planktonic ones. Sagitta macrocephala, for example, is found from the Arctic to the sub-Antarctic at a depth of $1,000-1,500 \mathrm{~m}$. It does not occur south of the Antarctic Convergence. Sagitta gazellae, which occurs on both sides of the Antarctic Convergence, provides an interesting example of incipient speciation as a result of a spatial barrier. It has formed two morphologically distinct races on the two sides, neither of which is numerous, in the region of the Convergence which separates them.

Analysing the data from the oceans of the world, he showed that the normal number of species found at any one station is about ten, and that in each oceanic area there is one species which is dominant. In cold waters the diversity is low and the dominant species accounts for as much as 85 per cent of the total chrtognath population compared with 40-50 per: cent in warm waters. Comparing the distributions of species in oceanic waters with those in neritic and mixed waters, Mr. David suggested that the species of the oceanic group, which are by far the most numerous, are the most closely adapted to their environment. Neritic and mixed-water groups are more capable of surviving in fluctuating conditions, and their less specialized adaptations are not able to survive competition against oceanic forms in the open ocean. Species are probably controlled by physical and chemical factors. not acting alone but in combination with biological factors including competition with other species.

J. M. Colebrook and G. A. Robinson discussed the specific treatment of data from the planktonic recorder and referred to the sub-speciation of Calanus finmarchicus. 